\title{
Erratum to: Woody and Herbaceous Plants of Inner Asia: Species Richness and Ecogeographic Patterns
}

\author{
D. V. Sandanov ${ }^{a, *}$, Y. Liu ${ }^{b, * *}$, Z. Wang ${ }^{b, * * *}$, and A. Yu. Korolyuk ${ }^{c, * * * *}$ \\ ${ }^{a}$ Institute of General and Experimental Biology, Siberian Branch, Russian Academy of Sciences, \\ Ulan-Ude, 670047 Republic of Buryatia, Russia \\ ${ }^{b}$ Institute of Ecology, College of Urban and Environmental Sciences, Peking University, Beijing, 100871 China \\ ${ }^{c}$ Central Siberian Botanical Garden, Siberian Branch, Russian Academy of Sciences, Novosibirsk, 630090 Russia \\ *e-mail: denis.sandanov@gmail.com \\ **e-mail: 18811378132@163.com \\ ***e-mail: zhiheng.wang@pku.edu.cn \\ ****e-mail: akorolyuk@rambler.ru
}

Submitted September 3, 2020; accepted for publication September 3, 2020

DOI: $10.1134 / \mathrm{S} 1995425520050121$

The title of the article should read as follows:

Woody and Herbaceous Plants of Inner Asia: Species Richness and Ecogeographic Patterns

The original article can be found online at

https://doi.org/10.1134/S1995425520040101 